\title{
Comparative study of Ropivacaine versus Bupivacaine for pediatric caudal block
}

\author{
Omar Elsafty MD, Ahmed M.S. Hamed MD, Sherif Wadie MD \\ \&Maged M.Kamel \\ Departement of anesthesia Ain shams university
}

\begin{abstract}
:
Ropivacaine is a long acting amino-amide local anesthetic, it is less cardiotoxic and less likely to cause motor blockade than bupivacaine.

In our study we compared the effectiveness, degree of motor block produced by either ropivacaine or bupivacaine as well as the onset and duration of both drugs.

Fourty children ASA I scheduled for elective minor lower abdominal surgery were randomly allocated to receive a single caudal extradural injection of $1 \mathrm{ml} / \mathrm{kg}$ of either ropivacaine $0.375 \% \mathrm{r}$ group $(\mathrm{n}=20)$ or bupivacaine $0.375 \%$ b group $(\mathrm{n}=20)$ after induction of general anesthesia.

Heart rate and arterial blood pressure were measured every 5 minutes from the beginning of G. A. until the child is transferred to the ward. The extent of motor block in the recovery room was scored according to modified Bromage scale, time to first analgesic requirement were recorded.

Both groups were similar in age, weight, and there were no difference in heart rate or arterial blood pressure. Yet the degree of motor block was significantly different between the two groups.

Ropivacaine group showed a shorter duration of motor block than bupivacaine group, postoperative analgesia was required at almost equal time in both groups. These findings suggest that there is no great difference between ropivacaine compared with bupivacaine as regard the hemodynamics or sensory block, yet ropivacaine is superior for it $\mathrm{s}$ safety and less motor block.
\end{abstract}

\section{Introduction:}

Ropivacaine is the s-enantiomer of amide local anesthetic, which has been extensively evaluated in adults and older children. Recently it has been used in younger children and several studies have reported its clinical efficacy and safety when administered for caudal epidural analgesia, for lumber epidural, for peripheral nerve block and as a continuous epidural infusion (1).

Ropivacaine has several properties which may be useful in pediatric practice, namely the potential to produce differential neural blockade with less motor block and reduced cardiovascular and neurological toxicity. (2) These features are particularly attractive for day case surgery in children, which is increasing in frequency.
Caudal analgesia is a relatively simple technique with a predictable level of blockade, provides excellent postoperative analgesia. It is the most popular regional anesthetic used in pediatric surgery for various surgical procedures, such as lower abdominal, urologic and lower limb operations. This long-acting regional technique provide analgesia beyond the duration of surgery, with a smooth recovery period and good postoperative pain control, and therefore reduces analgesic requirement and facilitates early discharge.

Long acting anesthetics, such as bupivacaine, have had a well-defined role in regional anesthesia and analgesia for many years. Since the report of several cases of systemic toxic reactions after 
accidental intravenous injections of bupivacaine, the need for an effective, long acting local anesthetic with high therapeutic ratio has prompted researchers to develope new local anesthetics (3).

The aim of our study was to determine the effectiveness of ropivacaine compared with bupivacane for caudal anesthesia in children as regard the onset, duration, sensory and motor blockade as well as the postoperative analgesia produced by each one of them.

\section{Material and methods:}

After obtaining written informed consent from the parents of the children, 40 children ASA I aged between 1-8 years undergoing elective lower abdominal surgery were selected to have caudal injection.

Intravenous infusion of $0.9 \%$ saline was established, anesthesia was induced either with inhalational mask of $\mathrm{O} 2 / \mathrm{NO} 2$ 1:1 ratio with sevoflurane, or intravenous propofol $2 \mathrm{mg} / \mathrm{kg}$ with lidocaine $0.5 \mathrm{mg} / \mathrm{kg}$. Tracheal intubation was facilitated with atracurium $0.5 \mathrm{mg} / \mathrm{km}$ and lungs ventilated artifitially with the previous $\mathrm{O} 2 / \mathrm{NO} 2$ sevoflurane mixture. No intravenous narcotics were given to the children.

Heart rate, noninvasive arterial blood pressure and oxygen saturation were monitored all through the operation and in the post- operative period.

After establishment of the anesthesia, children were turned to the left lateral position, sterilization of the lumbar and sacral area using povidone - iodine 10\% and toweling of the child with sterile towels, 22 gauge needle was inserted into the sacral hiatus and after testing the position of the needle for no aspirate of blood or CSF, the children were injected with $1 \mathrm{ml} / \mathrm{kg}$ of either $0.375 \%$ ropivacaine (r- group) (n-20) or $0.375 \%$ bupivacaine (bgroup) (n-20).

Recording the heart rate, blood pressure and $\mathrm{O} 2$ saturation were done every 5 min starting by the induction of anesthesia and till the child discharged from the recovery room. Motor weakness was determined according to modified bromage scale and the duration of postoperative analgesia using hourly observation of validate objective pain scale. Time to first micturation was calculated for both groups and observation were continued for $24 \mathrm{hrs}$.

\section{Results:}

Student $\mathrm{t}$ test and Wilcoxon test were used for continuous variables, including baseline characteristics, vital signs, durations of surgery, anesthesia, motor weakness, caudal analgesia and first micturition. Fisher exact test was used for categorical data such as gender, type of surgery. A P value $<0.05$ was considered statistically significant. All statistical data was carried out using SPSS for windows version 8 .

There were no differences between the two groups in age, weight, baseline blood pressure or heart rate; or durations of anesthesia and surgery (table 1). After surgical incision, the two groups did not differ in intraoperative vital signs (figure 1). None of the children developed a hemodynamic problem.

There was a significant difference in the degree of motor block between the two groups at 2; 3 and 4 hours after completion of surgery $(\mathrm{P}=0.012)$; as ropivacaine $(\mathrm{r}-$ group) showed a significant lesser motor block than bupivacaine (b- group) (figure 2).

The quality and duration of postoperative pain relief did not differ between the two groups at 1,2 or 3 hours after operation, or on discharge. The mean time from caudal placement to the first administration of analgesia postoperatively was $8.18 \pm 4.86$ hours in the bupivacaine group and $7.61 \pm 4.12$ hours in the ropivacaine group (table 2 ).

There was a significant difference between the two groups in mean time to first micturition $(4 \pm 2.3$ hours for bupivacaine group and $3.1 \pm 1.6$ hours in the ropivacaine group) (table 3 ). 
Table 1. Patient Characteristics and Clinical Parameters

\begin{tabular}{|l|l|l|}
\hline Variable & Group (b) & Group (r) \\
\hline Age (years) & $4 \pm 1.3$ & $5 \pm 2.1$ \\
\hline Weight (Kg) & $16 \pm 5$ & $17 \pm 6$ \\
\hline Anesthesia duration (min) & $56 \pm 24$ & $60 \pm 35$ \\
\hline Surgery duration (min) & $38 \pm 21$ & $36 \pm 19$ \\
\hline
\end{tabular}

Figure (1). Intraoperative Vital Signs (MAP = mean arterial blood pressure) and Pulse Rate in both groups. Values are mean $\pm \mathrm{SD}$.

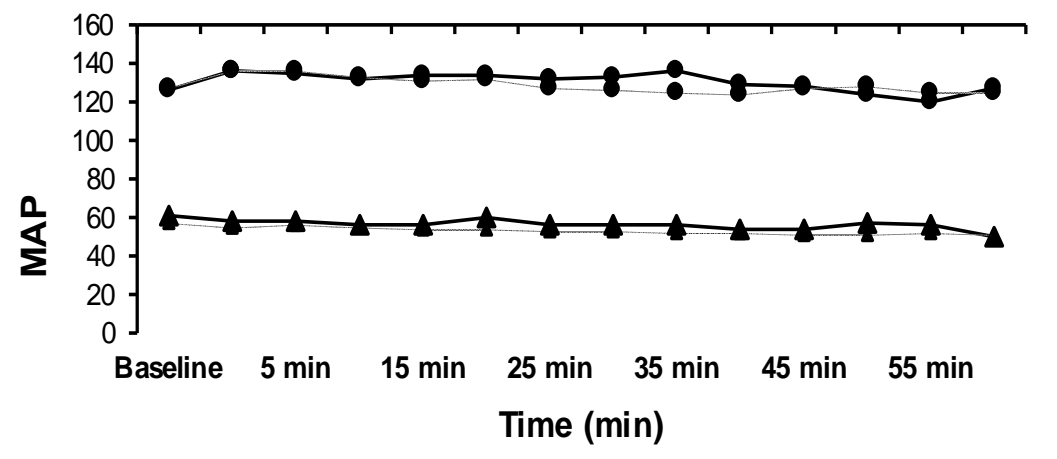

$\longrightarrow$ (b) MAP $\multimap$ (b) Pulse $\_$(r) MAP $\bullet$ (r) Pulse

\section{$\square($ b) group $\square(r)$ group}

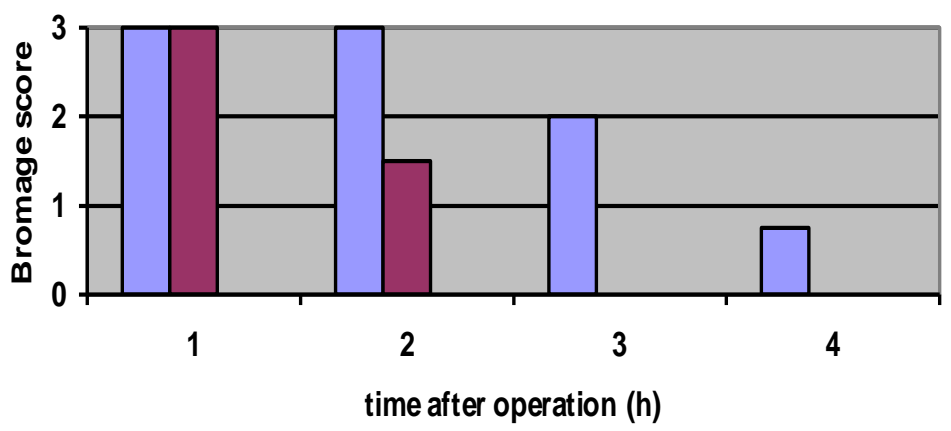

Figure (2). Motor block score on the postoperative period in the bupivacaine and ropivacaine groups

Table (2). Duration of analgesia and onset time with no statistical significant differences, expressed as mean \pm SD

\begin{tabular}{|l|l|l|}
\hline & (b) group & (r) group \\
\hline Onset (min) & $13.1 \pm 2.1(9-16)$ & $12 \pm 2.4(7-16)$ \\
\hline $\begin{array}{l}\text { Duration of analgesia } \\
\text { (hour) }\end{array}$ & $8.18 \pm 4.86$ & $7.61 \pm 4.12$ \\
\hline
\end{tabular}


Omar Elsafty et al

Table (3). Time to First Observation of Micturation after Caudal Injection

\begin{tabular}{|l|l|l|}
\hline & $(\mathrm{b})$ group & $(\mathrm{r})$ group \\
\hline Micturation time $(\mathrm{h})$ & $4 \pm 2.3$ & $3.1 \pm 1.6$ \\
\hline
\end{tabular}

\section{Discussion}

Ropivacaine $0.5 \%$ is considered an effective in term of duration of analgesia but accompanied with more extensive side effects. The time until voiding and the standing interval were significantly prolonged and motor block occurred in one child (3). Ivani and his colleague found that low concentration and large volumes are the key to obtain differential block in children because the small diameter of the A-delta and C -fibers and the small distance between the nodes of Ranvier, they found that $0.2 \%$ ropivacaine $1 \mathrm{ml} / \mathrm{kg}$ given as a single shot caudal extradural block is equivalent to the same volume of $0.25 \%$ bupivacaine. The lower intrinsic toxicity of ropivacaine and lower mas of drug needed gives an increased margin of safety which may be important, particularly in younger children(4).

In our study we increased the concentration of both drugs ropivacaine and bupivacaine so as to get more potent surgical analgesia with the prolonged postoperative sensory block compared with the previous concentration in the last study, also to get strong data about the motor blocking effect of each of the tested drugs. We found that both drugs had the same haemodynamic effects as regard heart rate, blood pressure and $\mathrm{O} 2$ saturation in both groups, the degree of sensory block were the same in both groups. Also postoperative analgesia was equal in both groups. Yet the degree of motor block was significantly different in both groups as ropivacaine group had less duration of motor block than bupivacaine. This was in agreement with Da-conceicao and his colleague study, they confirmed that ropivacaine administered to children by the caudal route, is an effective, long acting local anaesthetic, producing less duration of motor block than bupivacaine (5).

Khalil and his colleague using the same concentration of ropivacaine and bupivacaine $0.25 \%$ found that there were no significant difference between the two groups, the quality and duration of postoperative pain relief did not differ ,motor and sensory effects were similar. (6) This was in agreement with our study in all data collected but the motor blocking effect was significantly less in our study with ropivacaine than bupivacaine and this could be due to higher concentration of both drugs in our study.

As regard the voiding time, from our results we found a significant difference between (r-group) which had shorter time than (b-group), but non of both groups required urine catheterization. This was in contrast with the study performed by Khalil and his colleague (6) and Norton (1) who found that there was no difference between the two groups in mean time to first micturition between the two groups, again this may be explained by the higher concentration used in our study for both drugs.

In conclusion the results of our study suggest that $0.375 \%$ ropivacaine $1 \mathrm{ml} / \mathrm{kg}$ given as a single shot caudal extradural block is equivalent to the same volume and concentration of bupivacaine as regard haemodynamic stability, O2 saturation, sensory block, postoperative analgesia, yet it has shorter duration of motor block and time to first voiding is shorter in ropivacaine group than bupivacaine group. The lower intrinsic toxicity of ropivacaine gives an increased margin of safety, which is recommended particularly in young children. 


\section{References:}

1. Morton, NS. Ropivacaine in children. Br J Anaesth 2000; 85: 344 - 346

2. McClure JH. Ropivacaine. Br J Anaesth 1996; 76: 300 - 7

3. Koinig H, Krenn CG, Glaser C, Marhofer P, et al. the dose-response of caudal Ropivacaine in children. Anesthesiology 1999; 90: 1339 - 44

4. Ivani G, Lampugnani E, Torre M, Maria G, et al. comparison of ropivacaine with bupivacaine for pediatric caudal block. Br J Anaesth 1998; 81: 247 - 248

5. DaConceicao $M$ and Coelho $L$. Caudal anaesthesia with $\mathbf{0 . 3 7 5 \%}$ ropivacaine or $0.375 \%$ bupivacaine in pediatric patients. $\mathrm{Br} \mathrm{J}$ Anesth 1998; 80: 507 - 508

6. Khalil S, Campos C, Farag A, et al. caudal block in children: Ropivacaine compared with Bupivacaine. Anesthesiology 1999; 91: 1279 - 84 


\section{دراسة مقارنةبين عقار الروبيفاكين و عقار البيوبيفاكين في حالات التخدير الذيلي للأطفال}

\section{عمر الصفتى ، احمد شفيق حامد ، شريف وديع ، ماجد محسن

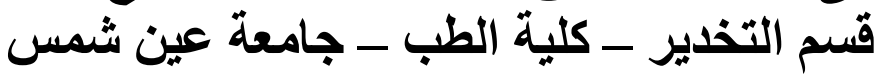

يعتبر عقار الروبيفاكين مخدر موضعي طويل المفعول و هو اقل ضررا على اليى

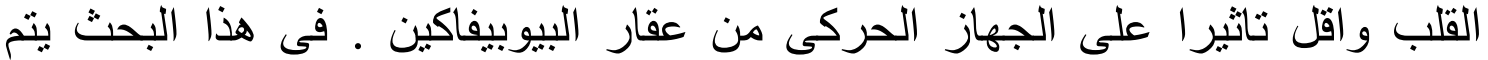
مقارنة عقار البيوبيفاكين بعقار الروبيفاكين من حيث قوة ومدة التانيثن على على الجهاز

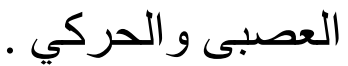

تم اختيار اربعون طفلا لاجر اء جراحات صغيرة بالجزء الاسفل من البطن وجهزوا

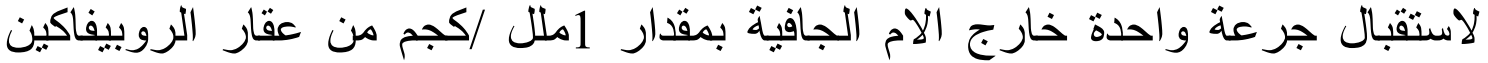

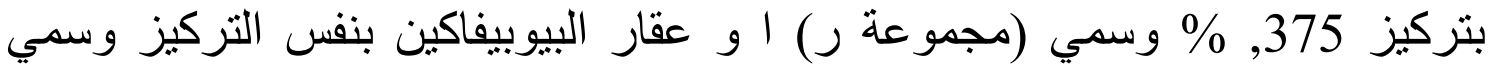

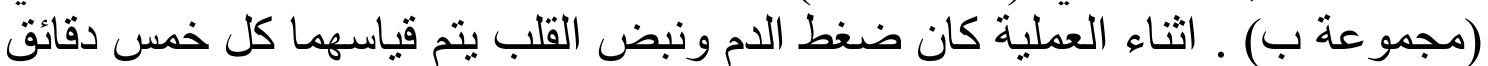

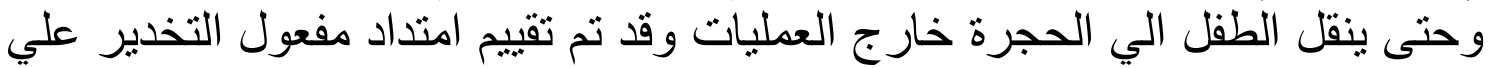

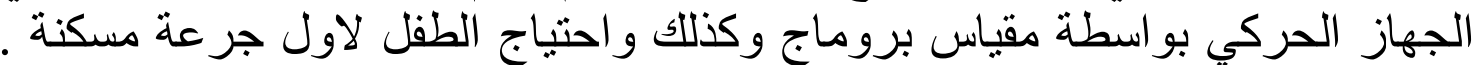

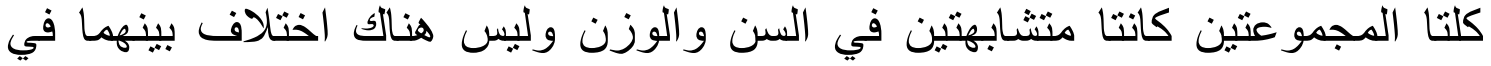

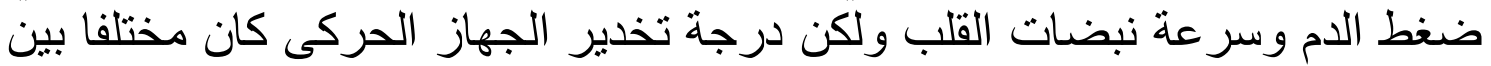

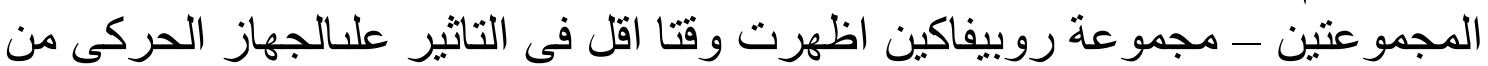

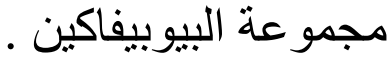
كما اظهر البحث ان وقت احتياج الطفل للجرعة المسكنة كان متماسلا فى كلتانيا

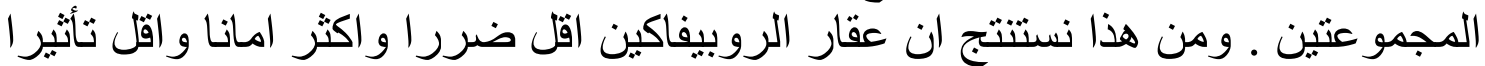
على الجهاز الحركي من عقار البيوبيفاكين. 